\title{
Future Euroson Schools
}

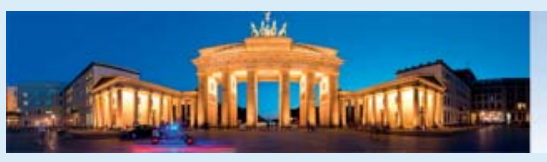

Interventional Ultrasound (INVUS)

EUROSON SCHOOL

Berlin, Germany 3 - 5 May 2018

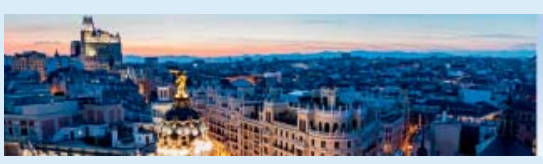

Dermatologic Ultrasound Course - Level 1

$$
\begin{array}{ll}
\text { EUROSON SCHOOL } \\
\text { Madrid, Spain } \quad 1 \text { - } 2 \text { June } 2018
\end{array}
$$

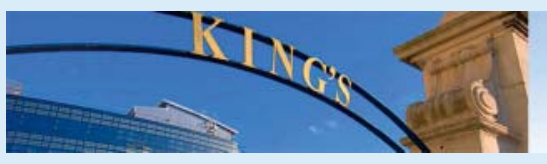

\section{2nd International CEUS Course \\ EUROSON SCHOOL \\ London, UK 11 - 12 June 2018}

